\title{
Effects of Acute Sleep Deprivation Resulting from Night Shift Work on Young Doctors
}

\author{
Efeitos Agudos da Privação de Sono Decorrente do Trabalho Nocturno em \\ Jovens Médicos
}

\author{
Inês SANCHES ${ }^{1}$, Fátima TEIXEIRA ${ }^{1,2}$, José Moutinho dos SANTOS ${ }^{2}$, António Jorge FERREIRA ${ }^{1,3}$ \\ Acta Med Port 2015 Jul-Aug;28(4):457-462
}

ABSTRACT

Introduction: To evaluate sleep deprivation and its effects on young physicians in relation to concentration capacity and psychomotor performance.

Material and Methods: Eighteen physicians aged 26 - 33 years were divided into 2 groups: non-sleep deprived group (with no night work) and sleep deprived group (minimum 12 hour of night work/week). We applied Pittsburgh Sleep Quality Index to screen the presence of sleep pathology and Epworth Sleepiness Scale to evaluate subjective daytime sleepiness; we used actigraphy and sleep diary to assess sleep hygiene and standard sleep-wake cycles. To demonstrate the effects of sleep deprivation, we applied ToulousePiéron's test (concentration test) and a battery of three reaction time tasks after the night duty.

Results: Sleep deprived group had higher daytime sleepiness on Epworth Sleepiness Scale $(p<0.05)$ and during week sleep deprivation was higher $(p<0.010)$. The mean duration of sleep during the period of night duty was 184.2 minutes to sleep deprived group and 397.7 minutes to non-sleep deprived group $(p<0.001)$. In the Toulouse-Piéron's test, the sleep deprived group had more omissions $(p<0.05)$ with a poorer result in concentration $(p<0.05)$. Psychomotor tests that evaluated response to simple stimuli revealed longer response latency $(p<0.05)$ and more errors $(p<0.05)$ in Sleep deprived group; in reaction to instruction test the sleep deprived group showed worse perfection index $(p<0.05)$; in the fine movements test there was no statistically significant difference between the groups.

Discussion: Acute sleep deprivation resulting from nocturnal work in medical professions is associated with a reduction in attention and concentration and delayed response to stimuli. This may compromise patient care as well as the physician's health and quality of life.

Conclusion: It is essential to study the effects of acute sleep deprivation on the cognitive abilities and performance of health professionals.

Keywords: Circadian Rhythm; Physicians; Sleep Deprivation; Sleep Disorders, Work Schedule Tolerance.

\section{RESUMO}

Introdução: Avaliar a privação do sono e seus efeitos sobre os jovens médicos relativamente à capacidade de concentração e desempenho psicomotor.

Material e Métodos: Dezoito médicos, com idades entre 26 - 33 anos, divididos em dois grupos: grupo sem privação de sono (sem trabalho nocturno) e grupo com privação de sono (no mínimo 12 horas de trabalho nocturno / semana). Aplicámos o Índice de Qualidade de Sono de Pittsburgh para rastrear a presença de patologia do sono e a Escala de Sonolência Epworth para avaliar subjectivamente a sonolência diurna; usamos actigrafia e o diário de sono para avaliar a higiene do sono e os ciclos de sono-vigília. Para demonstrar os efeitos da privação do sono, foi aplicado o teste de Toulouse-Piéron (teste de concentração) e uma bateria de três testes de tempo de reação após o período de trabalho nocturno.

Resultados: O grupo com privação de sono apresentou maior sonolência diurna na Escala de Sonolência Epworth $(p<0,05)$ e durante a semana a privação de sono foi maior $(p<0,010)$. A duração média do sono durante o período de trabalho nocturno foi de 184,2 minutos para o grupo com privação de sono e 397,7 minutos para grupo sem privação de sono $(p<0,001)$. No teste Toulouse-Piéron o grupo com privação de sono apresentou maior número de omissões $(p<0,05)$ com um pior resultado no índice de concentração $(p$ $<0,05)$. Os testes psicomotores que avaliaram a resposta a estímulos simples revelaram maior latência na resposta $(p<0,05)$ e mais erros $(p<0,05)$ no grupo com privação de sono; no teste de reacção a instrução o e grupo com privação de sono apresentou pior índice de perfeição $(p<0,05)$; no teste de movimentos finos não houve diferença estatisticamente significativa entre os grupos.

Discussão: A privação de sono aguda resultante do trabalho nocturno em profissões médicas está associada a uma diminuição da atenção e concentração e no atraso de resposta a estímulos. Isto pode comprometer o atendimento ao paciente, bem como a saúde e a qualidade de vida do próprio médico.

Conclusão: É essencial estudar os efeitos da privação aguda de sono sobre a capacidade cognitiva e de desempenho dos profissionais de saúde.

Palavras-chave: Médicos; Privação de Sono; Tolerância ao Trabalho Programado; Ritmo Circadiano; Transtornos do Sono.

\section{INTRODUCTION}

Sleep is an essential time, considered a fundamental biological need for survival and physical and mental wellbeing. Regeneration of neurons, consolidation of new

memories and formation of new synapses occur during the various stages of sleep. If REM sleep deprivation occurs there is decreased ability of perceptual learning, particularly

\footnotetext{
1. Pneumology Department. Centro Hospitalar e Universitário de Coimbra. Coimbra. Portugal.

2. Sleep Medicine Center. Centro Hospitalar e Universitário de Coimbra. Coimbra. Portugal.

3. Pneumology Department. Faculdade de Medicina. Universidade de Coimbra. Coimbra. Portugal

$\triangle$ Autor correspondente: Inês Sanches. inesanches83@gmail.com

Recebido: 30 de Agosto de 2014 - Aceite: 19 de Maio de 2015 | Copyright @ Ordem dos Médicos 2015
} 
assimilation and consolidation of information (memory). ${ }^{1}$ The deprivation of NREM slow-wave sleep, reduces the ability to perform tasks already learned or simple tasks related to animal survival. ${ }^{2}$

Published studies have shown that sleep deprivation is associated with decreased attention and vigilance, with impaired memory and decision making, slower reaction time and increased number of microsleeps during wakefulness. ${ }^{3}$ The sleep pattern is also altered, with difficulty in maintaining sleep, increased nighttime awakenings, terminal insomnia and daytime sleepiness ${ }^{4}$ that can lead to alcohol and other substance abuse. Sleep deprivation also appears to be associated with other comorbid states such as acute myocardial infarction, ${ }^{5}$ hypertension, ${ }^{6}$ obesity ${ }^{7}$ and glucose intolerance. ${ }^{8}$ Deficient sleep also may be associated to greater emotional lability with increased anxiety and depression. ${ }^{9}$ Dinges, ${ }^{10}$ among others, have shown that sleep deprivation is associated with an increased incidence of traffic accidents, ${ }^{11}$ comparable to driving under the influence of alcohol. ${ }^{12}$

The effect of sleep deprivation on performance of physicians has been the subject of many studies over the years, with mixed results. A possible explanation is the fact that these studies utilize a wide variety of methods in small samples making it difficult to validate results. Several studies have been carried out through the application of psychomotor tests applied to a doctor after sleep deprivation and showed decreased reaction time, increased response time variability and increase drowsiness ${ }^{10,13,14}$ Pilcher et al $^{15}$ published a meta-analysis that found that mood is more affected by sleep deprivation than either cognitive or motor performance and that partial sleep deprivation has a more profound effect on functioning than either longterm or short-term sleep deprivation. Ayas et al ${ }^{16}$ showed a higher incidence of medical errors including wrong decision making and needlestick incidents.

The objectives of this study are: Quantify sleep deprivation that occurs in physicians with night shift work; evaluate the effects of sleep deprivation with regards to concentration, response to simple stimuli and directional instructions and fine movements.

\section{MATERIAL AND METHODS}

This prospective study included a total of 22 physicians working in an emergency department of a Central Hospital. We included doctors under 35 years of age in order to standardize and avoid confounding factors such as age or professional experience since there are studies that associate increasing age with lower sleep efficiency and associate professional experience with different performance and anxiety/depression levels $1 .{ }^{7}$ The measured data were analyzed in two groups. The sleep deprived group (SDG) contained doctor that performed a minimum of 12 hour period of night work and with sleep deprivation (less than 5 hours of night sleep, $n=9$ ). The non-sleep deprived group [NSDG] included doctors with no night work and without sleep deprivation ( $\geq 5 \mathrm{~h}$ of night sleep, $\mathrm{n}=9$ ). ${ }^{18}$
Three physicians were excluded from the study because actigraphy signals were corrupted or lacking and one physician because presented acute sleep deprivation due to sleep fragmentation not related with night shift work.-

The threshold setting of acute sleep deprivation was less than 5 hours of night sleep since it is shown that this sleep deprivation is associated with adverse effects on cognitive functions and alertness. ${ }^{19}$

The ethics committee of the hospital approved the study protocol. The subjects participated in the study after providing written informed consent.

\section{Sleep}

In the first day (D1) subjects completed the Pittsburgh Sleep Quality Index (PSQI) ${ }^{20}$ to screen the presence of suspected sleep pathology and Epworth Sleepiness Scale (ESS) to evaluate subjective daytime sleepiness within the last month. ${ }^{14}$

Participants were requested to execute their job without restrictions. To assess sleep hygiene and standard sleepwake cycles subjects wore an actigraph $(A G)^{21,22}$ in the dominant arm (SenseWear ${ }^{\circledR}$ Pro2 Armband) and completed a sleep diary for 7 days prior to the period of emergency work evaluated (day 1 (D1) to day 8 (D8)). The sleep diary also asked to note the subjective sleep quality (scale from 0 'not very good' - 4 'very good') and well-being during the day (scale from 0 'not very good' - 4 'very good'). InnerView Body Media ${ }^{\circledR}$ software was used to score actigraph sleep and wake periods.

\section{Experimental day and performance measures}

On the seventh day (D7), SDG had a 12 hour period of night work and NSDG had no night work. At 9am of day 8 , to demonstrate the effects of sleep deprivation we applied the concentration test and psychomotor performance tests.

The Toulouse-Piéron test (TP) is used to assess visual attention, through a routine task that requires concentration and resistance to monotony. The test consists in identifying two symbols proposed between 1600 similar symbols, distributed over 40 lines in a 10 minute period. The parameters evaluated are the correct, wrong and omitted answers, allowing calculating a concentration index (wrong answers + omitted answers)/correct answers*100) and quality index (omitted answers/correct answers *100).

We used 3 of the 5 tests of the Battery Test Reaction $5^{\circledR}$ (version 1.0*2006) (Edipsico: Edições e investigação em Psicologia, Lda). These tests consisted of a computer control system that evaluated the ability of reaction to various stimuli. The reaction to simple stimuli test (StimulTest) evaluates the reaction to the colors and interpretation of the corresponding code. Reaction to instruction test (InstructTest) evaluates the response to stimuli implying sense of direction and the relative position of objects. The parameters evaluated in both tests are number of corrects and wrong answers, response latency (sec/answer) (calculated by $=180 /($ corrects + wrong $)$ ) and perfection index (\%) (calculated by correct/total of answers*100). The time 


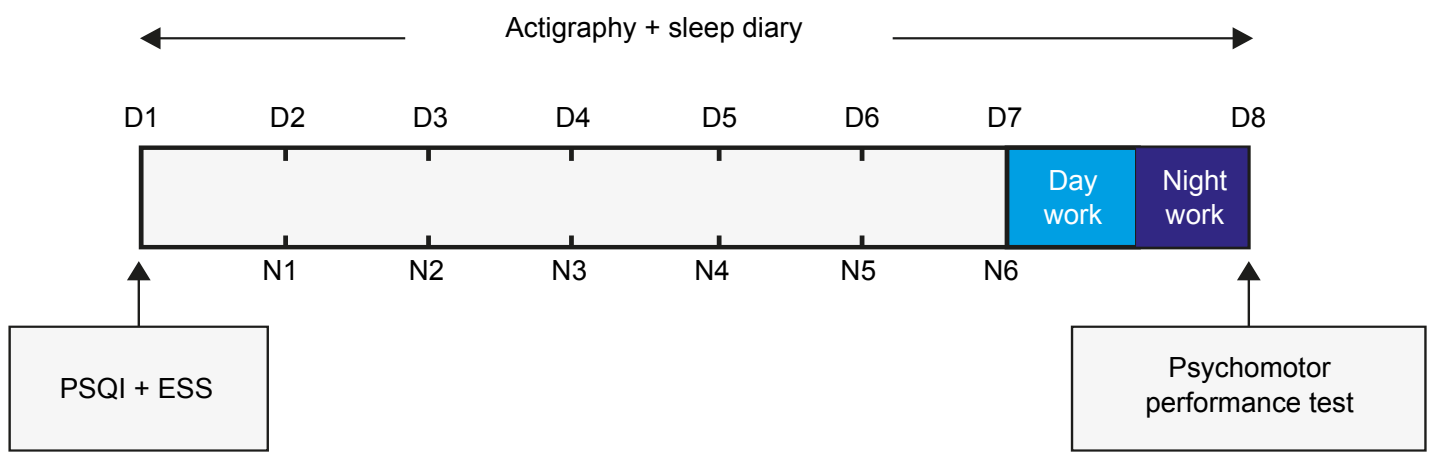

Figure 1 - Schematic diagram of the protocol for both groups D-day; N-hight; PSQI- Pittsburgh Sleep Quality; ESS- Epworth Sleepiness Scale

duration of each test is 3 minutes. Fine movements test (MovemTest) consists of performing, with the mouse of the computer, a narrow pathway in a straight line without exceeding the margins. The task should be performed in the shortest possible time and without errors. This test evaluates the strength and skill of the dominant hand and non-dominant hand. The parameters evaluated are number of errors and time spent in the test execution.

The tests used to assess the effects of sleep deprivation had a total duration of 18 minutes since studies indicate that the optimal duration of tests to assess cognition and sleep effects is $10-20$ minutes. ${ }^{23}$ (Fig. 1)

\section{Data analysis and statistical techniques}

Data were analyzed using software SPSS $^{\circledR}$ for Windows $^{\circledR}$ version 17.0. As two variables were compared, nonparametric Mann-Whitney $U$ test was applied to compare means. Chi square test and Fisher's exact test were applied to compare categorical variables and Kendall correlation to assess the strength of the linear relationship between actigraphy data and psychomotor test battery data. A significance level of 0.05 was used for all statistical tests. The sample size for each analysis was the number of physicians with and without sleep deprivation.

\section{RESULTS}

The study group included 13 women and 5 men, and had a mean age of $29.2 \pm 2.6$ years. There were no statistically significant differences between the two groups in terms of age, sex, body mass index and smoking habits (Table 1).

In the prior month, the SDG showed greater daytime sleepiness (ESS score $\geq 10$ : SDG 67\%, NSDG 11\%, $p=$ 0.05 ), and sleep quality was worse (PSQI score > 5: SDG $33 \%(n=3)$ NSDG vs. $0 \%(n=0), p>0.05)$.

\section{Sleep Data}

On the night before the performance tests (N7) the SDG subjects slept a mean of $187 \pm 87$ minutes while NSDG slept $398 \pm 58$ minutes $(p<0.001)$. On the 6 nights preceding N7, the SDG subjects also slept fewer hours. The duration and number of naps during week were higher in SDG ( $p$ $=0.010)$, but the number of total diurnal sleep hours was lower in SDG ( $p=0.038)$ (Table 2).

Regarding subjective sleep quality evaluated in sleep diary, SDG subjects said they had worse sleep quality on N7 (1.9 \pm 1.0 vs. NSDG $3.1 \pm 0.8, p=0.020)$, remaining statistically significant difference during the preceding week ( $2.6 \pm 0.3$ vs. $3.3 \pm 0.7, p=0.013)$. The SDG also felt worse after N7 (3.0 \pm 0.5 vs. NSDG $3.0 \pm 0.5, p=0.014)$. None of the subjects reported consuming psychoactive agents.

\section{Psychomotor Test Battery}

The psychomotor test battery results are shown in Table 3.

In the TP test the SDG had a greater number of omitted symbols $(p=0.034)$ and the results of Concentration Index

Table 1 - Sample characterization

\begin{tabular}{|c|c|c|c|c|c|}
\hline & & $\begin{array}{l}\text { NSDG } \\
(n=9)\end{array}$ & $\begin{array}{l}\text { SDG } \\
(n=9)\end{array}$ & $\begin{array}{c}\text { Total } \\
(n=18)\end{array}$ & $p$ \\
\hline \multicolumn{2}{|c|}{ Age, $x \pm S D$ years } & $29.0 \pm 2.8$ & $29.4 \pm 2.4$ & $29.2 \pm 2.6$ & $0.754^{*}$ \\
\hline \multirow{2}{*}{ Sex, n (\%) } & Female & $7(77.8)$ & $6(66.7)$ & $13(72.2)$ & \multirow[t]{2}{*}{$1.000^{* *}$} \\
\hline & Male & $2(22.2)$ & $3(33.3)$ & $5(27.8)$ & \\
\hline \multicolumn{2}{|c|}{ Smokers, n (\%) } & $0(0.0)$ & $1(5.6)$ & $1(5.6)$ & $1.000^{* *}$ \\
\hline \multicolumn{2}{|c|}{ BMI, $x \pm S D ~ K g / m^{2}$} & $21.9 \pm 2.6$ & $24.4 \pm 5.1$ & $23.1 \pm 4.1$ & $0.145^{*}$ \\
\hline
\end{tabular}


Table 2 - Actigraph registration

\begin{tabular}{|c|c|c|c|c|c|c|c|c|c|c|c|c|}
\hline \multirow[b]{2}{*}{ Night } & \multicolumn{2}{|c|}{$\begin{array}{l}\text { Night sleep } \\
\text { (min) }\end{array}$} & \multicolumn{4}{|c|}{$\begin{array}{l}\text { Naps } \\
\text { (n) }\end{array}$} & \multicolumn{3}{|c|}{$\begin{array}{l}\text { Naps duration } \\
\text { (min) }\end{array}$} & \multicolumn{3}{|c|}{$\begin{array}{l}\text { Total sleep in } 24 \text { hours } \\
\text { (min) }\end{array}$} \\
\hline & NSDG & SDG & $p$ & NSDG & SDG & $p$ & NSDG & SDG & $p$ & NSDG & SDG & $p$ \\
\hline $\mathrm{N}_{1-7}$ & $423.2 \pm 33.2$ & $344.6 \pm 59.1$ & 0.007 & 12 & 25 & 0.073 & 339 & 1962 & 0.010 & $428.6 \pm 30.1$ & $375.8 \pm 55.9$ & 0.038 \\
\hline $\mathrm{N}_{1-6}$ & $427.5 \pm 75.9$ & $371.4 \pm 119.6$ & 0.019 & 11 & 26 & 0.059 & 339 & 1935 & 0.010 & $433,8 \pm 29.5$ & $407.2 \pm 52.8$ & 0.200 \\
\hline 1 & $423.6 \pm 58.4$ & $374.2 \pm 116$ & 0.354 & 3 & 7 & 0.234 & 48 & 585 & 0.110 & $428.9 \pm 56.8$ & $439.2 \pm 90.5$ & 0.965 \\
\hline 2 & $423.7 \pm 61.1$ & $333.6 \pm 139.2$ & 0.453 & 0 & 4 & 0.066 & 0 & 425 & 0.067 & $413.7 \pm 61.1$ & $380.8 \pm 95.7$ & 0.566 \\
\hline 3 & $453.6 \pm 101.7$ & $330.3 \pm 115.7$ & 0.047 & 0 & 2 & 0.145 & 0 & 285 & 0.146 & $453.6 \pm 101.7$ & $362.0 \pm 70.0$ & 0.047 \\
\hline 4 & $444.9 \pm 81.0$ & $425.8 \pm 123.4$ & 0.566 & 4 & 5 & 0.647 & 232 & 326 & 0.678 & $470.7 \pm 95.7$ & $462.0 \pm 107.6$ & 0.965 \\
\hline 5 & $440.6 \pm 123.9$ & $351.1 \pm 135.1$ & 0.402 & 3 & 6 & 0.445 & 56 & 261 & 0.207 & $446.8 \pm 120.7$ & $380.1 \pm 125.4$ & 0.508 \\
\hline 6 & $388.7 \pm 29.1$ & $413.2 \pm 88.2$ & 0.566 & 1 & 1 & 1.000 & 3 & 53 & 0.936 & $389.0 \pm 28.7$ & $419.1 \pm 89.7$ & 0.453 \\
\hline 7 & $397.7 \pm 58.4$ & $184.2 \pm 87.0$ & 0.000 & 1 & 1 & 1.000 & 0 & 27 & 0.317 & $397.7 \pm 58.4$ & $187.2 \pm 87.2$ & 0.000 \\
\hline
\end{tabular}

Table 3 - Psychomotor test battery results

\begin{tabular}{|c|c|c|c|c|c|}
\hline & & & NSDG $(n=9)$ & SDG $(n=9)$ & $p$ \\
\hline \multirow{5}{*}{\multicolumn{2}{|c|}{ Toulouse- Piéron's test }} & Correct symbols (n) & $262.4 \pm 64.4$ & $237.4 \pm 56.3$ & 0.596 \\
\hline & & Wrong symbols (n) & $0.6 \pm 0.9$ & $2.1 \pm 4.2$ & 0.833 \\
\hline & & Omitted symbols (n) & $34.2 \pm 18.4$ & $62.7 \pm 44.0$ & 0.034 \\
\hline & & Concentration Index (\%) & $14.1 \pm 8.9$ & $30.0 \pm 25.9$ & 0.019 \\
\hline & & Quality Index (\%) & $13.8 \pm 8.6$ & $29.2 \pm 26.4$ & 0.031 \\
\hline \multirow{4}{*}{\multicolumn{2}{|c|}{ Reaction to instrutions test }} & Correct answer $(n)$ & $169.4 \pm 16.0$ & $148.3 \pm 28.3$ & 0.070 \\
\hline & & Wrong answer $(n)$ & $0.7 \pm 0.5$ & $1.4 \pm 1.2$ & 0.112 \\
\hline & & Perfection Index (\%) & $99.6 \pm 0.3$ & $98.9 \pm 1.3$ & 0.021 \\
\hline & & Response latency (sec/clic) & $1.07 \pm 0.1$ & $1.24 \pm 0.3$ & 0.070 \\
\hline \multirow{4}{*}{\multicolumn{2}{|c|}{ Reaction to simple stimuli test }} & Correct answer (n) & $170.7 \pm 21.9$ & $145.1 \pm 17.9$ & 0.022 \\
\hline & & Wrong answer $(n)$ & $1.0 \pm 1.0$ & $1.6 \pm 1.9$ & 0.0633 \\
\hline & & Perfection Index (\%) & $99.4 \pm 0.6$ & $98.9 \pm 1.5$ & 0.349 \\
\hline & & Response latency (sec/clic) & $1.06 \pm 0.1$ & $1.24 \pm 0.1$ & 0.022 \\
\hline \multirow{4}{*}{ Reaction to fine movements } & \multirow{2}{*}{ Left hand } & Errors $(n)$ & $4.8 \pm 5.0$ & $8.0 \pm 9.1$ & 0.588 \\
\hline & & Time (sec) & $14.3 \pm 8.2$ & $19.8 \pm 6.0$ & 0.101 \\
\hline & \multirow{2}{*}{ Right hand } & Errors $(n)$ & $4.7 \pm 5.8$ & $5.1 \pm 6.9$ & 0.891 \\
\hline & & Time (sec) & $17.2 \pm 12.9$ & $19.2 \pm 5.9$ & 0.250 \\
\hline
\end{tabular}

Concentration index $(\%)=\left[(\right.$ wrong + omitted $) /$ correct $\left.^{\star} 100\right]$; Quality index $(\%)=\left(\right.$ omitted $/$ correct $\left.^{\star} 100\right) ;$ Perfection $=\left(\right.$ correct/total of answers $\left.{ }^{\star} 100\right) ;$ Response latency $=180 /($ corrects + wrong).

and Quality Index were worse $(p<0.05)$. In InstructTest perfection index was worse in SDG $(p=0.021)$. In StimulTest the SDG also had fewer correct responses $(p=0.022)$, and the response latency was also higher $(p=0.022)$. With regards to MovemTest there were no statistically significant differences in several variables assessed.

Analyzing all the subjects, we found that the shorter duration of sleep in $\mathrm{N}_{7}$ is related with the largest number of omissions and worse Concentration and Quality Index of TP test $(p<0.05)$. In StimulTest and InstructTest, we also observed a low number of correct responses and an increased response latency related with shorter duration of sleep in $\mathrm{N}_{7}(p<0.05)$ (Table 4). Assessing these parameters within each group, this correlation persisted, but was not statistically significant. The PSQI and ESS did not correlate with the tests in the overall sample or within groups.

\section{DISCUSSION}

SDG had higher daytime sleepiness on ESS and during week sleep deprivation was higher. In the Toulouse-Piéron's test, SDG had more omissions with a poorer result in concentration. Psychomotor tests that evaluated response to simple stimuli revealed longer response latency and more errors in SDG; in reaction to instruction test the SDG showed worse perfection index; in fine movements test there was no statistically significant difference between the groups.

On $N_{7}$ the SDG had approximately 3 hours of night 
Table 4 - Correlation of the actigraphy results with psychomotor test battery results $(n=18)$

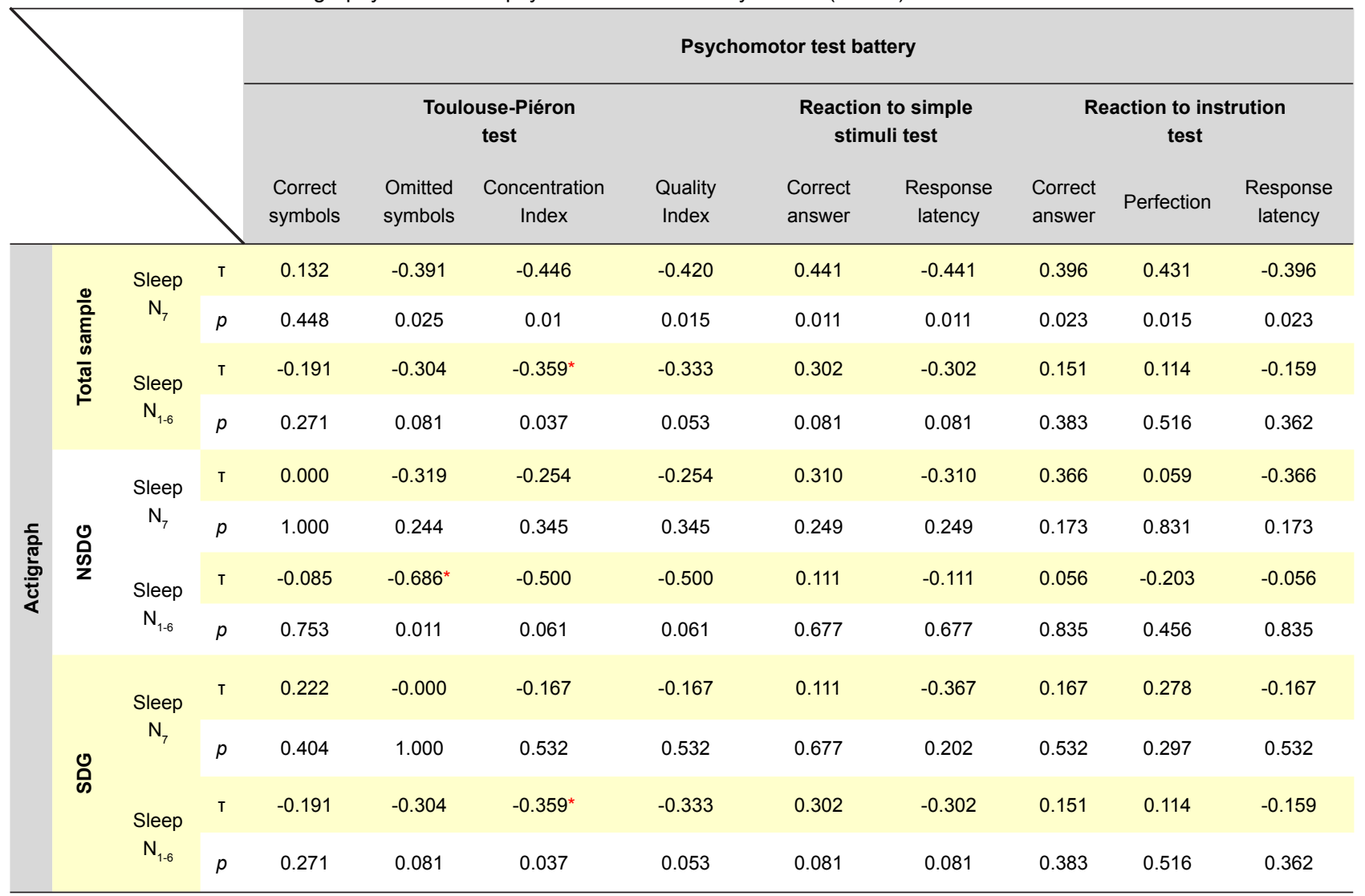

sleep while NSDG slept about 6 hours and 37 minutes, so the SDG had a partial sleep deprivation. ${ }^{15}$ However, we also found that in the remaining days of the week the SDG also had fewer hours of night sleep and, despite a greater number of hours of sleep in the day, the total daily sleep hours was also lower. Published studies have shown that sleep deprivation is associated with changes in sleep architecture, both night and day, thus lacking the physical, mental and emotional restorative effect. To minimize these effects, there is a tendency to sleep more during the day. However daytime sleep does not have the same quality that nighttime sleep has due to several factors, including difficulty in falling asleep during the day, shorter daytime sleep, early awakening and increased sleep fragmentation, and either for biological reasons (body temperature, hormonal circadian cycle) or exogenous reasons (more ambient noise, air temperature, social routines and eating behavior). ${ }^{17}$

In the subjective assessment of sleep quality and restorative effect of sleep, SDG scores showed worse sleep quality on most days and said they felt worse on the morning following sleep deprivation. The SDG also had greater daytime sleepiness evidenced in the previous month, which is in agreement with published studies. No subject reported taking psychoactive drugs, which provides greater reliability to the results since some studies suggest that psychoactive drugs alter the pattern of sleep and consequently induce changes in cognitive-mnemonic processing. ${ }^{25}$

With regards to the tests applied, the PT test, StimulTest and InstructTest have different designs but are intended to measure cognitive performance during a monotonous activity. In the PT test, SDG had a higher number of omissions and had Concentration Index over $20 \%$, implying a lack of deep concentration.

In StimulTest and InstructTest, the SDG had fewer correct answers in the execution of the given instruction and the reaction time was higher with less perfection in the execution of tasks. Probably the SDG had slower response to instructions in order to reduce mistakes. Published studies have shown that in fatigued workers the effectiveness in task performance is often sacrificed in favor of maintaining perfection in execution. ${ }^{26}$

In general, the SDG had worse performances in the assessment of attention/concentration, in the response to simple stimuli and orientation compared to NSDG. The effects of acute sleep deprivation (N7) are evaluated in all tests, while only the concentration parameter of TP test is influenced by the effects of chronic sleep deprivation. In a meta-analysis ${ }^{26}$ the authors found that tasks requiring high levels of continuous monitoring, long duration or require learning procedures appear to be more vulnerable to acute sleep deprivation. Veasey ${ }^{18}$ and Muecke ${ }^{27}$ concluded that acute sleep deprivation causes increased reaction times, with decreased ability to concentrate, slurred speech and a greater number of errors in executions. In addition simple tasks were performed more slowly, revealing decreased fine motor ability. These data are consistent with those observed in our study. 
A limitation of the study was the adopted methodology, as there are few studies that evaluate the effects of acute sleep deprivation measured for the Portuguese population and the majority use subjective questionnaires. It is necessary to standardize a battery of practice tests that can assess more concise results across studies.

\section{CONCLUSION}

Medical practice implies a significant amount of sleep deprivation and many health professionals are unaware of the its harmful effects, both for themselves and for their patients, threatening good clinical practice. It is, therefore, essential to study the effects of acute sleep deprivation on the cognitive abilities and performance of health professionals. The paucity of practical and objective research on the effects of acute sleep deprivation is clearly demonstrated above show the vital importance of this study for the medical community.

\section{REFERENCES}

1. Peigneux $P$, Smith $C$. Memory processing in relation to sleep. In: Kryger MH, Roth T, Dement WC, editors. Principles and Practice of Sleep Medicine. $5^{\text {th }}$ ed. Philadelphia: Saunders; 2011. p. 335-44.

2. Santos MI. Distúrbios do padrão de sono nos enfermeiros trabalhadores por turnos. Dissertação de Mestrado. Coimbra: Faculdade de Medicina da Universidade de Coimbra; 2007.

3. Roehrs T, Carskadon MA, Dement WC, Roth T. Daytime sleepiness and alertness. In: Kryger MH, Roth T, Dement WC, editors. Principles and practice of sleep medicine. $5^{\text {th }}$ ed. Philadelphia: Saunders; 2011. p. $42-51$.

4. Goel N, Rao H, Durmer JS, Dinges DF. Neurocognitive consequences of sleep deprivation. Semin Neurol. 2009;29:320-39.

5. Godinho A. Factores preditivos das consequências do trabalho por turnos. Dissertação de Mestrado em Psicologia Clínica. Coimbra: Faculdade de Psicologia da Universidade de Coimbra; 2006.

6. Liu Y, Tanaka H, The Fukuoka Heart Study Group. Overtime work, insufficient sleep, and risk of non-fatal acute myocardial infarction in Japanese men. Occup Environ Med. 2002;59:447-51.

7. Gangwisch JE, Heymsfield SB, Boden-Albala, Buijs RM, Kreier F, Pickering TG, et al. Short sleep duration as a risk factor for hypertension: analysis of the first National Health and Nutrition Examination Survey. Hypertension. 2006;47:833-9.

8. Taheri S, Lin L, Austin D, Young T, Mignot E. Short sleep duration is associated with reduced leptin, elevated ghrelin, and increased body mass index. PLoS Med. 2004;1:e62.

9. Knutson $\mathrm{KL}$, Van Cauter E. Associations between sleep loss and increased risk of obesity and diabetes. Ann N Y Acad Sci. 2008;1129:287-304.

10. Kahn-Greene ET, Killgore DB, Kamimori GH, Balkin TJ, Killgore WD. The effects of sleep deprivation on symptoms of psychopathology in healthy adults. Sleep Med. 2007;8:215-21.

11. Onen $\mathrm{SH}$, Onen $\mathrm{F}$, Courpron $\mathrm{P}$, Dubray $\mathrm{C}$. How pain and analgesics disturb sleep. Clin J Pain. 2005;21:422-31.

12. Dinges DF. An overview of sleepiness and accidents. J Sleep Res. 1995;4:4-14

13. Steele MT, Ma OJ, Watson WA, Thomas HA Jr, Muelleman RL. The occupational risk of motor vehicle collisions for emergency medicine residents. Acad Emerg Med. 1999;6:1050-3.

14. Arnedt JT, Owens J, Crouch M, Stahl J, Carskadon MA. Neurobehavioral performance of residents after heavy night call vs

\section{PEOPLE AND ANIMALS PROTECTION / CONFIDENTIA- LITY OF DATA}

The ethics committee of the hospital approved the study protocol. The subjects participated in the study after providing written informed consent. The authors declare having followed the protocols in use at their working center regarding patient's data publication.

\section{CONFLICTS OF INTEREST}

The authors declare that there are no conflicts of interest.

\section{FUNDING SOURCES}

No subsidies or grants contributed to this work.

after alcohol ingestion. JAMA. 2005;294:1025-33.

15. Gaba DM, Howard SK. Fatigue among clinicians and the safety of patients. N Engl J Med. 2002;347:1249-55.

16. Leff DR, Aqqarwal R, Rana M, Nakhjavani B, Purkayastha S, Khullar $V$, et al. Laparoscopic skills suffer on the first shift of sequential night shifts: program directors beware and residents prepare. Ann Surg. 2008;247:530-9.

17. Murray WJ. A new method for measuring daytime sleepiness: the Epworth sleepiness scale. Sleep. 1991:14:540-5.

18. Pilcher JJ, Huffcutt AL. Effects of sleep deprivation on performance: a meta-analysis. Sleep. 1996;19:318-26.

19. Ayas NT, Barger LK, Cade BE, Hashimoto DM, Rosner B, Cronin JW, et al. Extended work duration and the risk of self-reported percutaneous injuries in interns. JAMA. 2006;296:1055-62.

20. Veasey S, Rosen R, Barzansky B, Rosen I, Owens J. Sleep loss and fatigue in residency training: a reappraisal. JAMA. 2002;288:1116-24.

21. Buysse DJ, Reynolds CF, Monk TH, Berman SR, Kupfer DJ. The Pittsburgh Sleep Quality Index: a new instrument for psychiatric practice and research. Psychiatry Res. 1989;28:193-213.

22. Littner M, Kushida CA, Anderson WM, Bailey D, Berry RB, Davila DG et al. Practice parameters for the role of actigraphy in the study of sleep and circadian rhythms: an update for 2002. Sleep. 2003;26:337-41.

23. Reid K, Dawson D. Comparing performance on a simulated 12 hour shift rotation in young and older subjects. Occup Environ Med. 2001;58:58-62.

24. Loh S, Lamond N, Dorrian J, Roach G, Dawson D. The validity of psychomotor vigilance tasks of less than 10-minute duration. Behav Res Methods Instrum Comput. 2004;36:339-46.

25. Dru M, Bruge P, Benoit O, Mason NP, Combes X, Margenet A, et al Overnight duty impairs behaviour, awake activity and sleep in medical doctors. Eur J Emerg Med. 2007;14:199-203.

26. Monk TH, Buysse DJ. Sleep deprivation and performance of residents. JAMA. 1989;261:860-1.

27. Kripke DF, Simons RN, Garfinkel L, Hammond EC. Short and long sleep and sleeping pills. Is increased mortality associated? Arch Gen Psychiatry. 1979;36:103-16.

28. Owens JA. Sleep loss and fatigue in medical training. Curr Opin Pulm Med. 2001:7:411-8.

29. Muecke S. Effects of rotating night shifts: literature review. J Adv Nurs. 2005;50:433-9. 
Inês SANCHES, Fátima TEIXEIRA, José Moutinho dos SANTOS, António Jorge FERREIRA

\section{Effects of Acute Sleep Deprivation Resulting from Night Shift Work on Young Doctors}

Acta Med Port 2015:28:457-462

Publicado pela Acta Médica Portuguesa, a Revista Científica da Ordem dos Médicos

Av. Almirante Gago Coutinho, 151

1749-084 Lisboa, Portugal.

Tel: +351218428215

E-mail: submissao@actamedicaportuguesa.com

www.actamedicaportuguesa.com

ISSN:0870-399X | e-ISSN: 1646-0758

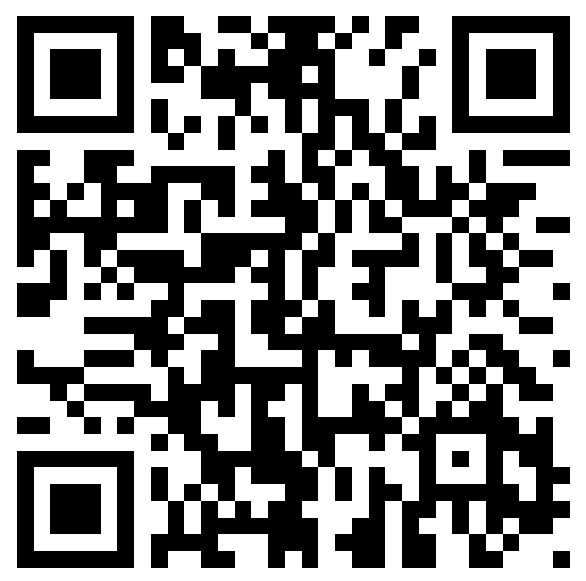

ACTA MÉDICA

PORTUGUESA 